\section{Antigen Capture Assay}

T. Arndt

Institut für Medizinische Diagnostik GmbH, Bioscientia, Ingelheim, Deutschland

Englischer Begriff antigen capture assay

Definition Variante des heterogenen Immunoassays zum Nachweis von Antigenen.

Beschreibung Die Durchführung erfolgt als $>$ SandwichAssay. Ein für das zu bestimmende $>$ Antigen spezifischer - Antikörper ist an eine Festphase (Röhrchenwand oder Mikrotiterplattenkavität) fixiert. Nach Zugabe der $>$ Patientenprobe bindet das in ihr enthaltene Antigen an diesen Antikörper. Nach einem Spülschritt wird ein zweiter, gegen das Antigen gerichteter, markierter (z. B. mit einem Enzym oder radioaktiven Isotop oder mit einer fluoreszierenden oder chemilumineszierenden Gruppe) Antikörper zugegeben.

Dieses Prinzip ist in vielen $>$ Immunoassays verwirklicht, z. B. dem immunoradiometrischen Assay (IRMA), dem
- Enzyme-linked Immunosorbent Assay (ELISA) oder dem immunoluminometrischen Assay (ILMA). Detektierbar sind mit dem Antigen Capture Assay nur Antigene, die mindestens zwei antigene Determinanten aufweisen, also in der Lage sind, zwei Antikörper zu binden.

Den einzelnen Assayschritten sind Inkubationszeiten und Waschschritte zur Entfernung unspezifischer und ungebundener Probenbestandteile zwischengelagert. Das an den Antikörper gekoppelte Enzym kann z. B. eine Phosphatase oder Peroxidase sein, die in der Lage sind, durch Substratumsatz eine Änderung der Farbe oder der Farbintensität des Reaktionsansatzes herbeizuführen (ELISA). Diese ist, wie die Radioaktivität ( $\triangleright$ Radioimmunoassay), die $\triangleright$ Chemolumineszenz oder die $>$ Fluoreszenz direkt proportional zur Menge des zu bestimmenden Antigens.

\section{Literatur}

Marja E. Koivunen, Richard L. Krogsrud, (2006) Principles of Immunochemical Techniques Used in Clinical Laboratories. Laboratory Medicine 37(8):490-497 